\title{
A Systematic Approach to Interpreting the Cardiopulmonary Exercise Test in Pediatrics
}

Citation for published version (APA):

Van Brussel, M., Bongers, B. C., Hulzebos, E. H. J., Burghard, M., \& Takken, T. (2019). A Systematic Approach to Interpreting the Cardiopulmonary Exercise Test in Pediatrics. Pediatric Exercise Science, 31(2), 194-203. https://doi.org/10.1123/pes.2018-0235

Document status and date:

Published: 01/05/2019

DOI:

10.1123/pes.2018-0235

Document Version:

Publisher's PDF, also known as Version of record

Document license:

Taverne

Please check the document version of this publication:

- A submitted manuscript is the version of the article upon submission and before peer-review. There can be important differences between the submitted version and the official published version of record.

People interested in the research are advised to contact the author for the final version of the publication, or visit the DOI to the publisher's website.

- The final author version and the galley proof are versions of the publication after peer review.

- The final published version features the final layout of the paper including the volume, issue and page numbers.

Link to publication

\footnotetext{
General rights rights.

- You may freely distribute the URL identifying the publication in the public portal. please follow below link for the End User Agreement:

www.umlib.nl/taverne-license

Take down policy

If you believe that this document breaches copyright please contact us at:

repository@maastrichtuniversity.nl

providing details and we will investigate your claim.
}

Copyright and moral rights for the publications made accessible in the public portal are retained by the authors and/or other copyright owners and it is a condition of accessing publications that users recognise and abide by the legal requirements associated with these

- Users may download and print one copy of any publication from the public portal for the purpose of private study or research.

- You may not further distribute the material or use it for any profit-making activity or commercial gain

If the publication is distributed under the terms of Article $25 \mathrm{fa}$ of the Dutch Copyright Act, indicated by the "Taverne" license above, 


\title{
A Systematic Approach to Interpreting the Cardiopulmonary Exercise Test in Pediatrics
}

\author{
Marco Van Brussel \\ University Medical Center Utrecht \\ Bart C. Bongers \\ Maastricht University \\ Erik H.J. Hulzebos, Marcella Burghard, and Tim Takken \\ University Medical Center Utrecht
}

\begin{abstract}
The use of cardiopulmonary exercise testing in pediatrics provides critical insights into potential physiological causes of unexplained exercise-related complaints or symptoms, as well as specific pathophysiological patterns based on physiological responses or abnormalities. Clinical interpretation of the results of a cardiopulmonary exercise test in pediatrics requires specific knowledge with regard to pathophysiological responses and interpretative strategies that can be adapted to address concerns specific to the child's medical condition or disability. In this review, the authors outline the 7-step interpretative approach that they apply in their outpatient clinic for diagnostic, prognostic, and evaluative purposes. This approach allows the pediatric clinician to interpret cardiopulmonary exercise testing results in a systematic order to support their physiological reasoning and clinical decision making.
\end{abstract}

Keywords: child, exercise physiology, interpretation, normal responses, differential diagnosis

Within pediatric medicine, clinical exercise physiology is a discipline in which the integrated response of various physiological systems (pulmonary, cardiovascular, hematologic, metabolic, and musculoskeletal) is objectively assessed and analyzed at rest, during progressive exercise, and during recuperation, often using cardiopulmonary exercise testing (39). Using this noninvasive and dynamic integrative approach, it is possible to uncover potential physiological causes of unexplained exercise-related complaints and symptoms and to observe specific pathophysiological patterns based on physiological responses or abnormalities (39). Furthermore, this integrated approach provides the clinician with a broad spectrum of information to support their physiological reasoning and clinical decision making. Children can be referred for a cardiopulmonary exercise test (CPET) for the purposes of differential diagnostics, prognostics, as well as for the evaluation of intervention effectiveness (see Table 1 for a detailed overview of indications for a CPET).

In children, growth and maturation lead to notable physiological, anatomical, and psychological changes that can significantly alter both the responses to exercise and overall exercise capacity.

\footnotetext{
Van Brussel, Hulzebos, Burghard, and Takken are with the Department of Medical Physiology, Child Development and Exercise Center, Wilhelmina Children's Hospital, University Medical Center Utrecht, Utrecht, The Netherlands. Bongers is with the Department of Epidemiology, Faculty of Health, Medicine and Life Sciences, Care and Public Health Research Institute (CAPHRI), Maastricht University, Maastricht, The Netherlands; and the Department of Nutrition and Human Movement Sciences, NUTRIM School of Nutrition and Translational Research in Metabolism, Faculty of Health, Medicine and Life Sciences, Maastricht University, Maastricht, The Netherlands. Van Brussel (m.vanbrussel@umcutrecht.nl) is corresponding author.
}

This differs considerably from exercise testing in adults. Therefore, knowledge concerning normal and abnormal responses to exercise as well as appropriate sex- and age-related reference values is vital for clinical interpretation, especially in children with a medical condition or a disability. Given the richness and complexity of pediatric CPET data, it is essential to apply a systematic and comprehensive approach to the interpretation of these tests (16). Therefore, the aim of this article is to provide a general guide for the systematic interpretation of CPET data based on the approach we have developed and applied over the last 15 years for diagnostic, prognostic, and evaluative purposes in pediatrics.

\section{CPET in Children}

Performing a CPET in children, especially in younger and smaller children, can be challenging since they do not always adhere to the standard operating procedures or fit the standard CPET equipment (eg, face masks, cycle ergometer) or consumables (electrocardiogram electrodes). Indeed, while equipment or consumables, protocols (see below), and reference values (9) should be age and weight appropriate, there is a lack of robust reference values from large samples of children, especially younger age groups (eg, 4-8 y) and those of various ethnic backgrounds. A CPET in very young children may not always be appropriate because they tend to be less cooperative compared with older children, demonstrate frequent changes in cadence, and in our experience, will often talk during the test. Perhaps more importantly, young children might not have the experience of performing progressive or intensive exercise and might therefore stop the CPET prematurely, before giving a true cardiovascular maximal effort. Experience 


\section{Table 1 Indications to Perform CPET in Pediatric Medicine}

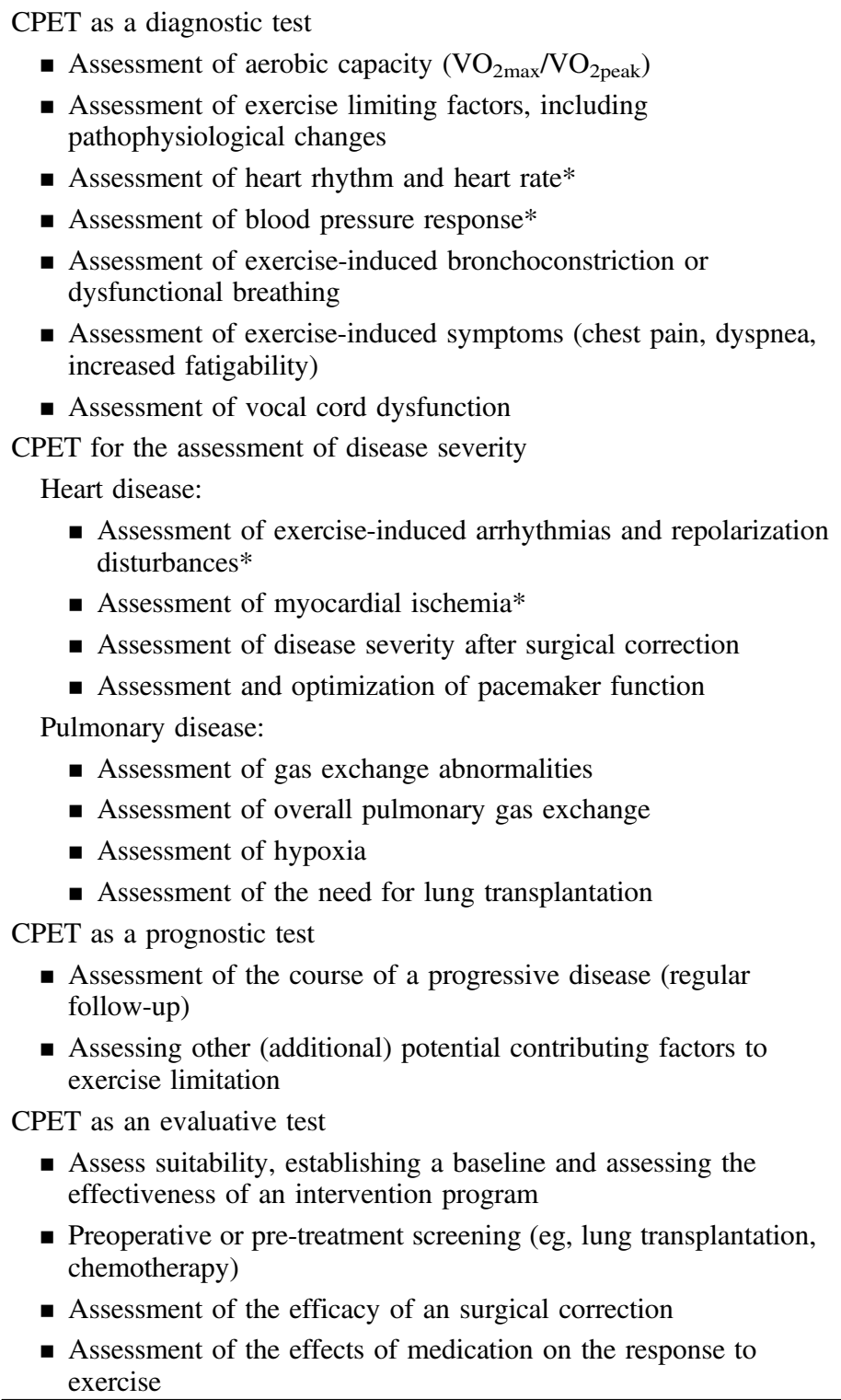

Abbreviations: CPET, cardiopulmonary exercise testing; $\mathrm{VO}_{2 \max }$, maximal oxygen uptake; $\mathrm{VO}_{2 \text { peak }}$, oxygen uptake at peak exercise. Note: Adapted from Bongers et al (9).

*Also applicable in case of an exercise test with electrocardiogram only (without respiratory gas analysis measurements).

with carefully handling, supporting, and encouraging young children is vital for valid exercise testing.

There are a number of CPET protocols, and many exercise laboratories use their own standardized tests. When the child's performance is compared with reference values, it is necessary to standardize the CPET protocol to match the testing procedures and methodology that were used to establish the reference values (9). It is also important to select an appropriate CPET protocol that will allow for evaluation of child's complaints and symptoms, while also considering their current physical fitness. For example, although the Bruce protocol is the most frequently used treadmill protocol for a CPET in children and adolescents (12) for differential diagnostics in pediatrics, a cycle ergometer is strongly preferred. The cycle ergometer possesses multiple clinical advantages over treadmill testing in pediatric clinical settings, including the fact that the test will not be constrained by mechanical limitations of a patient (eg, inefficient gait; deformities; soreness in ankles, knees, and hip; or balance problems); the risk for injuries is considered negligible; peak work rate $\left(\mathrm{WR}_{\text {peak }}\right)$ can be obtained precisely; and it is easier to obtain better quality physiological measurements including electrocardiography and blood pressure (eg, less movement artifacts) $(3,29,47)$. Furthermore, for young children, next to the lack of familiarity, the speed of the treadmill protocol is often a restrictive factor. When performing a CPET using a cycle ergometer, the Godfrey protocol (21) is frequently used in children and adolescents. A contemporary modification is the ramp Godfrey protocol. In the ramp modification, there is smaller increase in the work rate (WR) in shorter intervals $(2-4 \mathrm{~W} / 12 \mathrm{~s})$ instead of increases per minute; this protocol is more compatible with modern electronically braked cycle ergometers equipped with automated protocols. Importantly, the ramp modification allows for a more precise examination of the patient's exercise response, especially in those with more severe limitations and/or deconditioning. In addition to an electronically braked cycle ergometer, CPET equipment should include a metabolic cart able to analyze respired gases (oxygen $\left[\mathrm{O}_{2}\right]$ and carbon dioxide $\left[\mathrm{CO}_{2}\right]$ ) with a rapid response time $(<90 \mathrm{~ms})$ to provide breath-by-breath measurements of ventilatory gas exchange variables, as well as ancillary equipment for serial monitoring of electrocardiogram, blood pressure, and peripherally measured oxygen saturation $\left(\mathrm{SpO}_{2}\right)(25)$.

\section{Standardized Interpretative Strategy}

Optimal utilization of CPET data requires valid and reliable collection and presentation of the data in a clear and standardized approach that is sufficiently flexible to apply to a variety of pathophysiological conditions (16). Below, we describe the 7-step interpretation strategy for a pediatric CPET (see Figure 1) that we use in our outpatient clinic, which is inspired by the approach described by Cooper and Storer (14).

\section{Step 1: Rationale for Requesting a CPET}

There are numerous indications for requesting a CPET within pediatric medicine (Table 1). In fact, there are more childhood than adulthood disorders in which a CPET is of clinical relevance (6). The most common indications are to support differential diagnosis for idiopathic exercise-related complaints and symptoms (eg, dyspnea, tachycardia, chest pain, muscle pain or cramps, syncope, fatigue) or exercise-induced abnormalities (eg, severe muscle pain, arrhythmias, bronchoconstriction), for prognostic (monitoring disease status) or for evaluative purposes (eg, efficacy of interventions). When a patient is referred for a CPET, the rationale for referral should be clear to allow the administering clinician to assess the feasibility of the request and avoid any invalid or unnecessary use of the CPET. Information regarding patient history; clinical status (eg, pulmonary function tests, resting electrocardiogram, blood tests); the level of habitual physical activity and sports participation; exercise-related complaints and symptoms; and any clinical contraindications for the CPET should be provided, when applicable. For pretest data collection, the recommendations by Levett et al (25) can be used. Furthermore, we recommend the use of a pediatric preparticipation screening questionnaire for both children and parents/guardians before commencing each clinical CPET (see Appendix). 


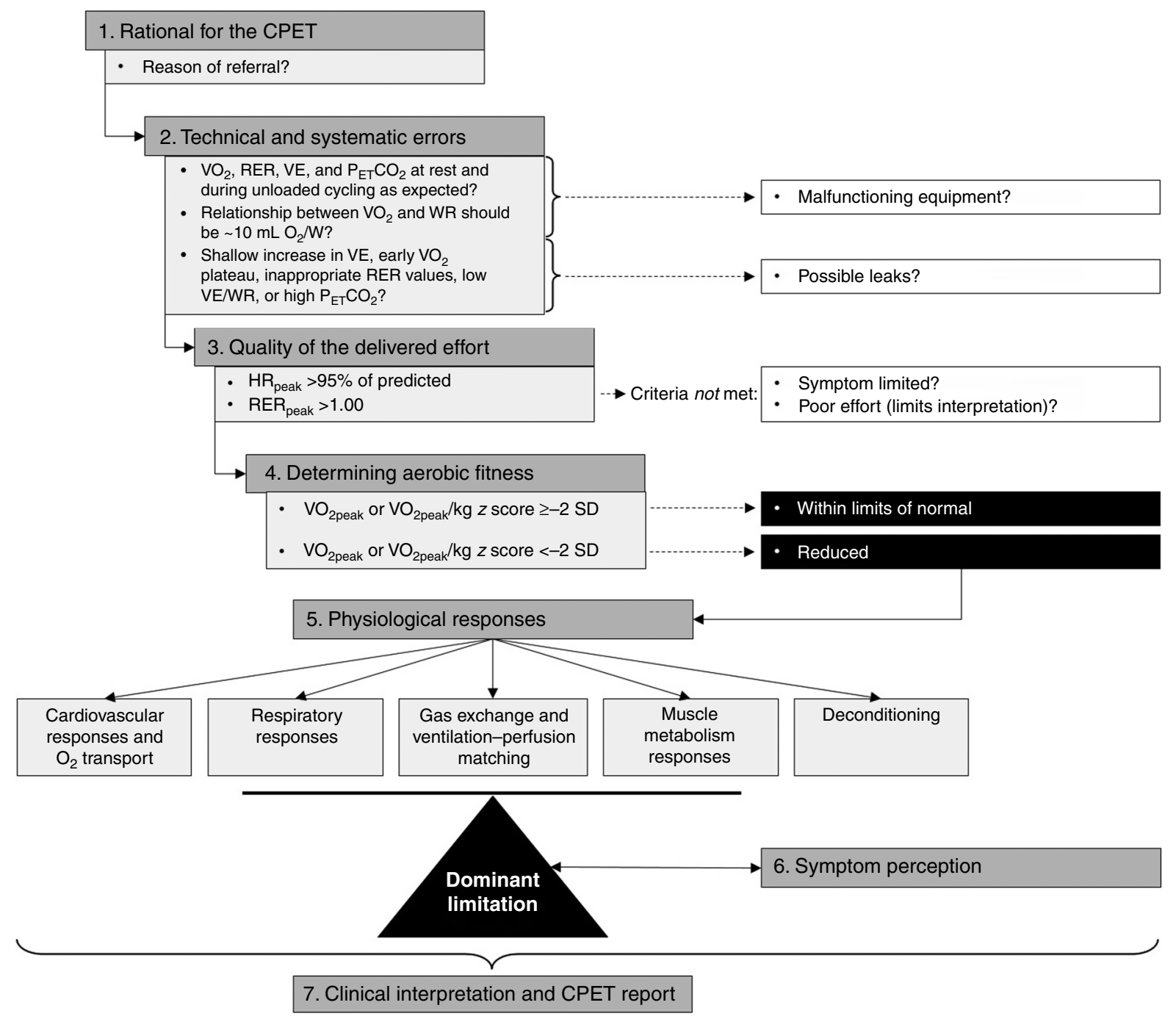

Figure 1 - The 7-step interpretative strategy for pediatric CPET. CPET, cardiopulmonary exercise testing; $\mathrm{HR}_{\text {peak }}$, heart rate at peak exercise; $\mathrm{P}_{\mathrm{ET}} \mathrm{CO}_{2}$, partial end-tidal carbon dioxide tension; RER, respiratory exchange ratio; $\mathrm{RER}_{\text {peak }}$, RER at peak exercise; VE, minute ventilation; VE/WR, minute ventilation to work rate ratio; $\mathrm{VO}_{2}$, oxygen uptake; $\mathrm{VO}_{2}$ peak, oxygen uptake at peak exercise.

\section{Step 2: Technical and Systematic Errors}

To avoid potential technical and systematic errors, calibration of primary sensors for flow as well as $\mathrm{O}_{2}$ and $\mathrm{CO}_{2}$ concentration measurements must be completed before every test. The flow sensor must be calibrated for volume with a precision syringe $(3 \mathrm{~L})$ over a physiological range of flow rates, including a very low flow rate for young children. Calibration gas mixtures for the $\mathrm{O}_{2}$ and $\mathrm{CO}_{2}$ sensors must be prepared by gravimetric weighting to ensure a concentration accuracy of $\pm 1 \%$. Sensor calibration must be performed at 2 points, within the range of inhaled $\left(21 \% \mathrm{O}_{2}\right.$ and $0 \% \mathrm{CO}_{2}$ in $\left.\mathrm{N}_{2}\right)$ and exhaled gas compositions $\left(15 \% \mathrm{O}_{2}\right.$ and $5 \% \mathrm{CO}_{2}$ in $\left.\mathrm{N}_{2}\right)(25)$.

Throughout the CPET, it is important to continually verify that oxygen uptake $\left(\mathrm{VO}_{2}\right)$, respiratory exchange ratio (RER), minute ventilation (VE), and partial end-tidal $\mathrm{CO}_{2}$ tension $\left(\mathrm{P}_{\mathrm{ET}} \mathrm{CO}_{2}\right)$ are within reasonable limits. In addition, the relationship between $\mathrm{VO}_{2}$ and WR should be linear, at approximately $10 \mathrm{~mL} \mathrm{O}_{2} / \mathrm{W}$ (47). Unexpected values in the previously mentioned parameters could indicate malfunctioning of the equipment or, in some cases, may reflect pathophysiology. For example, a shallow increase in VE, a very early plateau in $\mathrm{VO}_{2}$, nonphysiological RER values (eg, $<0.70$ ), low VE to $\mathrm{WR}$, or high $\mathrm{P}_{\mathrm{ET}} \mathrm{CO}_{2}$ values could indicate possible leaks in the testing system or the need to recalibrate the metabolic cart. We recommend testing for mask leaks before every test using visual inspection of the connection between the face mask and the nose. After fitting and visual inspection of the face mask, leaks can be ruled out by asking the child to inhale completely, covering the opening of the face mask gently with the palm of your hand (without the flow-volume transducer attached to it), then asking the child to exhale forcefully for 2 seconds while listening for audible gas leaks. In the event of a leak, adjust the mask and retest for leakage.

\section{Step 3: Quality of the Delivered Effort}

For an appropriate interpretation of CPET data, it is essential to determine whether the child performed a maximal or near maximal effort. The appearance of a plateau in $\mathrm{VO}_{2}$ during a progressive CPET, despite an increase in WR, has conventionally been 
considered the best indicator for a maximal effort $\left(\mathrm{VO}_{2} \mathrm{max}\right)(3)$. However, only a minority of children attain a true plateau in $\mathrm{VO}_{2}$ during a CPET $(4,32)$. Therefore, peak oxygen uptake $\left(\mathrm{VO}_{2}\right.$ peak) is often used as a substitute for $\mathrm{VO}_{2} \max (4,32)$. Nevertheless, the absence of $\mathrm{a} \mathrm{VO}_{2}$ plateau at the end of the CPET makes it difficult to determine whether a child performed an effort at, or near, their maximal level.

In pediatric populations, heart rate $(\mathrm{HR})$ at peak exercise $\left(\mathrm{HR}_{\text {peak }}\right)$ and the RER at peak exercise $\left(\mathrm{RER}_{\text {peak }}\right)$ are recommended as additional objective criteria to assess the quality of the performed effort (3). More specifically, a HR of at least 180 beats/min at $\mathrm{VO}_{2}$ peak (or more accurately $\geq 95 \%$ of predicted $\mathrm{HR}_{\text {peak }}$ ) (19) and RER of at least 1.00 at $\mathrm{VO}_{2}$ peak represent the absolute lower limits of normal during a CPET using cycle ergometry. While maximal HR decreases with age in adults (42), average maximal HR remains relatively stable, around 195 to 197 (bicycle) to 200 beats/min (treadmill), in children and adolescents $(9,19,24)$. The RER $\left(\mathrm{VCO}_{2} / \mathrm{VO}_{2}\right)$ at rest ranges from 0.70 to 0.85 , depending on the timing and the type of food consumed or the degree of insulin resistance (33). Therefore, patients should be advised not to eat for up to 2 hours before commencing the CPET. During progressive exercise, $\mathrm{VCO}_{2}$ increases relative to $\mathrm{VO}_{2}$, which translates into an increase in RER, this reflects a shift in substrate utilization from primarily free fatty acids to mainly glucose, as well as buffering $\mathrm{H}^{+}$ ions from anaerobic glycolysis (47). An attained RER of $\geq 1.00$ at $\mathrm{VO}_{2}$ peak $\left(\mathrm{RER}_{\text {peak }}\right)$ indicates the reliance on glycolytic energy provision and typically occurs after the ventilatory anaerobic threshold (VAT). However, a value of 1.00 is the lowest limit of normal $(9,46)$, values $<1.00$ at $\mathrm{VO}_{2}$ peak could indicate a submaximal effort or could be pathological (eg, glycogen storage disease). In healthy children and adolescents, the mean value for RER at $\mathrm{VO}_{2}$ peak ranges from 1.14 to 1.19 , with a mean of 1.16 $(9,22)$. It is critical that $\mathrm{RER}_{\text {peak }}$ is assessed at the point of $\mathrm{VO}_{2}$ peak, since RER values rise directly after cessation of the CPET and during the recovery phase. Indeed, the RER can "overshoot" up to values $>1.50$, which is attributable to the delayed recoveries of $\mathrm{VCO}_{2}$ and $\mathrm{VE}$ and the comparatively rapid recovery of $\mathrm{VO}_{2}$ (37). It is therefore also important to avoid complete cessation of exercise upon attainment of $\mathrm{VO}_{2}$ peak. Rather, the child should be instructed to continue light exercise at a low WR (eg, 5-10 W) for at least 5 minutes to balance the recovery times of $\mathrm{VCO}_{2}, \mathrm{VE}$, and $\mathrm{VO}_{2}$, and ensure clearance of metabolic byproducts (like $\mathrm{H}^{+}$ions and $\mathrm{CO}_{2}$ ). In children and adolescents, RER values will decrease within 2 to 3 minutes of recovery.

A second option to confirm whether the attained $\mathrm{VO}_{2}$ peak reflects true $\mathrm{VO}_{2}$ max is to administer a supramaximal exercise to exhaustion with respiratory gas analysis following the CPET (5). However, this is often not feasible in clinical practice due to the limited stamina of the patient or due to time limitations. Subjective visual indicators of the delivered effort (eg, sweating, flushing) and reason(s) for exercise cessation indicated by the patient are also important parameters to verify the quality of the delivered effort. It is important to keep in mind that when verifying the quality of the delivered effort in children with a potential medical condition, the previously mentioned values may not always be achieved due medication usage (eg, $\beta$-blockers) or underlying pathophysiology.

\section{Step 4: Determining Aerobic Fitness}

When performing a CPET in children, the observed level of aerobic fitness is of great clinical relevance, wherein an abnormal value provides the impetus to further examine CPET data to uncover the physiological mechanisms underlying this impairment. In case of a maximal effort (step 3), the clinical exercise physiologist can pragmatically evaluate the child's aerobic fitness based on $\mathrm{VO}_{2}$ peak, where a $\mathrm{VO}_{2}$ peak $(\mathrm{mL} / \mathrm{kg} / \mathrm{min}$ and $\mathrm{L} / \mathrm{min})$ of $\geq-2 \mathrm{SD}$ falls within limits of normal $(8,9)$. The frequent use of $80 \%$ of predicted as the lower limit of normal is not recommended, since this value overestimates the lower limit of normal in adolescents (T. Takken, unpublished data, November 2018). When $z$ scores of $\mathrm{VO}_{2}$ peak are $<-2 \mathrm{SD}$, it is imperative to analyze additional CPET data to determine the most limiting physiological factor. It is important to note that CPET data should always be extensively analyzed, even when $\mathrm{VO}_{2}$ peak falls within the normal range, since patients with an athletic background who have higher than normal $\mathrm{VO}_{2}$ peak values may also present with underlying physiological abnormalities or deficits (eg, palpitations, hyperventilation).

In case of a submaximal effort during CPET, conclusions concerning aerobic fitness based on $\mathrm{VO}_{2}$ peak cannot be drawn, and these data should be interpreted with caution. Other CPET parameters such as the VAT and the oxygen uptake efficiency slope (1) can be used to provide an indication of fitness.

\section{Step 5: Determining Physiological Limitations}

Detailed analysis of the CPET data can provide insight into the physiological response that contributes most dominantly to reported or observed exercise limitations. For clinical and pragmatic reasons, these limitations can be subdivided in cardiovascular responses and oxygen transport, respiratory responses, gas exchange and ventilation-perfusion matching, and muscle metabolism responses. In addition, deconditioning should also be included as a possible exercise-limiting factor, as this is often inherent to a chronic medical condition. When evaluating the dominant physiological limitation, algorithmic approaches that emphasize a primary mechanism or exercise limitation may be helpful; however, these are usually inadequate as they are based on adult cutoff values, exercise intolerance is multifactorial, and single abnormalities in CPET outcomes can be observed in multiple medical conditions. Therefore, a combination of multiple outcomes is necessary to determine the most dominant limitation.

Cardiovascular Responses and Oxygen Transport. When examining the cardiovascular responses during a CPET, it is important to analyze the HR response at rest, during progressive exercise, and during recovery. It is also vital to realize that maximal $\mathrm{HR}$ is genetically predetermined and that the maximal HR achieved by children and adolescents is independent of age. During moderate exercise intensity, $\mathrm{HR}$ is usually linearly related with $\mathrm{VO}_{2}$ (47). Therefore, oxygen pulse $\left(\mathrm{O}_{2}\right.$ pulse $\left.=\mathrm{VO}_{2} / \mathrm{HR}\right)$ should increase with exercise and gradually level off to a (near) plateau at peak exercise. A decrease in $\mathrm{O}_{2}$ pulse during progressive exercise could be an indicative of circulatory failure (7), and in combination with a sudden decrease in the $\mathrm{VO}_{2}$ to $\mathrm{WR}$ ratio $\left(\Delta \mathrm{VO}_{2} / \Delta \mathrm{WR}\right)$, could be indicative of myocardial ischemia (7). Furthermore, $\mathrm{O}_{2}$ pulse should be within normal limits $\left(\geq-2\right.$ SD) as a low $\mathrm{O}_{2}$ pulse is indicative of a reduced cardiac stroke volume (44). However, in conditions with reduced oxygen extraction (eg, mitochondrial myopathies), $\mathrm{O}_{2}$ pulse might not be a good reflection of stroke volume. Determination of stroke volume during exercise using continuous echocardiography or emerging bioimpedance methods is performed infrequently in clinical practice but might help to enhance the diagnostic utility of CPET for cardiac abnormalities. Circulatory abnormalities like low cardiac output are also often reflected in a high $\mathrm{VE} / \mathrm{VCO}_{2}$ slope. We highly recommended 
examining the electrocardiogram (12 lead) for abnormalities (eg, arrhythmias, ST changes, and ectopy) at rest, during progressive exercise, and during recovery for at least 5 minutes. In case of suspected electrocardiogram abnormalities, always consult a pediatric cardiologist and apply relative and absolute contraindications before and during exercise $(20,38)$.

Blood pressure response during progressive exercise is also an important circulatory parameter. Systolic blood pressure should increase with exercise intensity $(\sim 30 \mathrm{~mm} \mathrm{Hg} / 100 \mathrm{~W})$, with a marked increase above the VAT (23). Although it is difficult to obtain valid measurements of diastolic blood pressure during exercise, this value should remain stable. A decrease or a failure to increase systolic pressure might indicate clinically significant left ventricular dysfunction (13). Finally, peripherally measured $\mathrm{SpO}_{2}$ should always be monitored during a CPET, ideally using a forehead sensor. A decrease in $\mathrm{SpO}_{2}>4 \%$ from baseline represents abnormal desaturation (3), and the CPET should be terminated if $\mathrm{SpO}_{2}$ falls $<80 \%$ and is accompanied by symptoms and signs of severe hypoxemia (3), as recommended by the American Thoracic Society (ATS) guidelines.

Respiratory Responses. In healthy children who exercise at sea level, there is no respiratory limitation to $\mathrm{VO}_{2}$. Although a respiratory limitation is not likely, complete lung function testing before a CPET is strongly recommended. Lung function testing should include assessments of respiratory muscle strength, body plethysmography, spirometry (prebronchodilator and postbronchodilator medication), and diffusing capacity. These measures will help determine whether there is abnormal lung function and/or respiratory muscle weakness, as well to estimate maximal voluntary ventilation (MVV; see below). In addition, different CPET parameters can be utilized to verify whether there is suspicion or indication of respiratory limitation or abnormal respiratory response to exercise.

Respiratory limitation should always be interpreted in relation to a child's actual ventilatory capacity rather than to normal predicted values. For instance, a child with obstructive pulmonary disease can be expected to have a reduced ventilatory capacity but may or may not have a ventilatory limitation. A ventilatory limitation is traditionally defined by a limited $(<20 \%)$ ventilatory reserve (VR) during exercise (11). The VR is calculated as VR $=1-$ $\left(\mathrm{VE}_{\text {peak }} / \mathrm{MVV}\right)$, where $\mathrm{VE}_{\text {peak }}$ is the maximal volume of air exhaled per minute at peak exercise (MVV $=\mathrm{FEV}_{1} \times 35$ in children) (11). Healthy children have a VR of at least $11 \mathrm{~L} / \mathrm{min}$ or $20 \%$ to $40 \%$ of their MVV. A low VR is characteristic of patients with primary lung disease, with the smallest VR observed in obstructive lung disease, whereas a high VR occurs when cardiovascular or other conditions limit exercise performance (43). Clinically, this outcome is very helpful in distinguishing cardiac from pulmonary disease and should therefore be included as part of the interpretation process.

Children with evidence of pulmonary disease during the CPET can demonstrate a wide variety of exercise patterns depending on the predominant mechanism of exercise limitation and disease severity. Most often, these children present with a low VR and a high $\mathrm{HR}$ reserve $\left(\mathrm{HRR}=\right.$ predicted maximal $\left.\mathrm{HR}-\mathrm{HR}_{\text {peak }}\right)$, increased physiological dead space ventilation to tidal volume ratio (VD/VT $>0.34$ ), and increased arterial to end-tidal partial $\mathrm{CO}_{2}$ tension differences (45). In early obstructive lung disease (higher residual volume or residual volume to total lung capacity ratio), for example, CPET responses may be normal, but exercise flow-volume loops can demonstrate expiratory flow limitation. Expiratory flow limitation corresponds to the part of the tidal flow-volume loop that meets or exceeds the expiratory boundary of the maximal flow-volume loop and is expressed as a percentage of the tidal volume (11). Post-CPET spirometry can also be helpful to identify postexercise bronchospasm in children who have exercise-induced bronchoconstriction and/or occult asthma and/or who are receiving inadequate asthma medication.

In general, children with restrictive lung diseases have reduced exercise capacity, a low $\mathrm{VO}_{2}$ peak, and a low VAT. In these children, tidal volume increases to its maximum (50\% of the vital capacity and/or $80 \%$ of the inspiratory capacity) at a relatively low WR $(17,27,30)$. Any further increase in VE is due to an increase breathing frequency $(\mathrm{BF}) . \mathrm{BF}$ is age dependent and is approximately 65 breaths/min in 5- to 8-year-old children and between 50 and 55 breaths/min in children $>11$ years of age (31). If there is a ventilatory limitation during exercise, $\mathrm{SpO}_{2}$ decreases systematically at each WR when there is shunting or mismatching (34).

Dyspnea can be assessed during CPET. Typically, there is a lag before the sense of respiratory effort increases. In children, this lag occurs at about $40 \%$ of maximal ventilation (43), whereas it occurs between $20 \%$ and $40 \%$ of maximal ventilation in adults. While there is no consensus on the definition of dysfunctional breathing during exercise, the demonstration of a rapid shallow breathing pattern is often used for confirmation. Nevertheless, breathing pattern may vary with age, wherein normal BF is higher in younger children because of a lower tidal volume (39). To assess breathing pattern, it is important to evaluate the tidal volume to vital capacity ratio in the context of age and determine its link to wasted ventilation (ie, increased demand).

Gas Exchange and Ventilation-Perfusion Matching. Gas exchange via diffusion from the lungs to the blood and vice versa is important for maintaining homeostasis during exercise. For the interpretation of gas exchange data, the following parameters are considered: ventilatory equivalents for $\mathrm{O}_{2}$ (ventilatory efficiency; $\mathrm{VE} / \mathrm{VO}_{2}$ ) and $\mathrm{CO}_{2}$ (ventilatory drive; $\mathrm{VE} / \mathrm{VCO}_{2}$ ), the partial endtidal $\mathrm{CO}_{2}$ tension $\left(\mathrm{P}_{\mathrm{ET}} \mathrm{CO}_{2}\right)$, and the partial end-tidal $\mathrm{O}_{2}$ tension $\left(\mathrm{P}_{\mathrm{ET}} \mathrm{O}_{2}\right)(3)$. Low ventilatory efficiency (ie, high $\mathrm{VE}$ for $\left.\mathrm{VO}_{2}\right)$ and high ventilatory drive (ie, high $\mathrm{VE}$ for $\mathrm{VCO}_{2}$ ) are indications of abnormal gas exchange in the lungs (14). These are commonly observed with pulmonary vascular abnormalities like pulmonary hypertension. End-tidal gas tensions are a good reflection of arterial gas tensions when the child has a normal diffusion capacity in the lungs (14). Low $\mathrm{P}_{\mathrm{ET}} \mathrm{CO}_{2}$ and high $\mathrm{P}_{\mathrm{ET}} \mathrm{O}_{2}$ in combination with a high RER are indicators of hyperventilation (3). Assessment of arterial blood gasses can help to discriminate between hyperventilation and ventilation-perfusion mismatch with a low $\mathrm{P}_{\mathrm{ET}} \mathrm{CO}_{2}$. In children who hypoventilate, a low $\mathrm{P}_{\mathrm{ET}} \mathrm{O}_{2}$ and a high $\mathrm{P}_{\mathrm{ET}} \mathrm{CO}_{2}$ is observed (47).

The VD/VT ratio is valuable for estimating the degree of mismatch in ventilation to perfusion during exercise. At rest, physiological dead space ventilation is normally about one-third of the tidal volume (VD/VT at rest is about 0.34 ), this is reduced to about one-fifth during progressive exercise (VD/VT during exercise is $<0.24)(10)$. For children who cannot achieve $\mathrm{VO}_{2}$ peak, a potential alternative marker is ventilatory drive or the $\mathrm{VE} / \mathrm{VCO}_{2}$ ratio at the $\mathrm{VAT}$. The $\mathrm{VE} / \mathrm{VCO}_{2}$ slope up to the respiratory compensation point represents the ventilatory efficiency throughout the CPET up to the point where compensatory hyperventilation for metabolic acidosis begins (36). Several studies suggest that VE during exercise is mainly regulated to maintain the arterial pressure of $\mathrm{CO}_{2}$ close to resting levels (41). Indeed, $\mathrm{VE}$ is altered by produced $\mathrm{CO}_{2}$, which results in a close linear relation between $\mathrm{VE}$ and $\mathrm{VCO}_{2}$ up to the respiratory compensation point $(18,35,36)$. Since the arterial pressure of $\mathrm{CO}_{2}$ is tightly regulated up to the respiratory compensation point, higher $\mathrm{VE} / \mathrm{VCO}_{2}$ at the respiratory 
compensation point is usually due to a higher VD/VT (35), which represents an inefficiency of ventilation due to ventilationperfusion mismatching or right-to-left shunting (3). The latter reduces the efficiency of lung gas exchange and requires an increase in $\mathrm{VE}$ to maintain a given $\mathrm{VCO}_{2}$ and arterial pressure of $\mathrm{CO}_{2}$.

Muscle Metabolism Responses. When muscle metabolism or myopathies are suspected sources of limitations, a CPET can be helpful to unravel abnormalities (40). Parameters of interest during CPET include a reduced $\mathrm{VO}_{2}$ peak, low VAT, and abnormally high or low blood lactate levels. In several myopathies, the $\Delta \mathrm{VO}_{2} / \Delta \mathrm{WR}$ ratio is low, and in contrast to cardiovascular disorders, the $\Delta \mathrm{VCO}_{2} / \Delta \mathrm{WR}$ ratio is also low. This is because reduced muscle blood flow prevents the locally released $\mathrm{CO}_{2}$ to be observed at the level of lung gas exchange. In contrast to primary heart disease, the HR reserve is generally high because exercise is terminated before the cardiovascular system is maximally stressed (eg, due to leg pain). Finally, there is often a large VR because the demand on the respiratory system is usually relatively low. However, for diagnostic purposes, additional blood and urine samples should be collected before and after the CPET to measure lactate, ammonia, and creatine kinase among other metabolites (40). Abnormal RER values during progressive exercise and during recovery can also indicate metabolic abnormalities; for example, very high or low RER values during submaximal exercise could be indicative for a fatty acid oxidation disorder, mitochondrial myopathy, or glycogen storage disease, respectively $(15,28)$.

Deconditioning. Deconditioning can be a major limiting factor in many children with a medical condition. Deconditioning is broadly defined as a reduced capacity of cardiovascular oxygen transport and/or a reduced efficiency in peripheral oxygen extraction with an early onset of the VAT $(20,45)$. A VAT $<50 \%$ of predicted $\mathrm{VO}_{2}$ peak is associated with deconditioning, whereas a VAT $<40 \%$ of predicted may be indicative significant deconditioning or of pathology (26).

Understanding the role of deconditioning in the exerciseinduced physiological responses during a CPET is of great clinical importance, since observed deficits in CPET outcomes may be attributable to the deconditioning itself or to physiological abnormalities. In case of deconditioning, physical exercise training can be effectively prescribed as part of treatment. During exercise, the combination of a decreased $\mathrm{O}_{2}$ pulse at peak exercise $(<-2 \mathrm{SD}$ of predicted), a decreased VAT $\left(<40-50 \%\right.$ of predicted $\mathrm{VO}_{2}$ peak), decreased $\mathrm{VO}_{2}$ peak normalized for body mass, decreased WR at peak exercise normalized for body mass $(<-2 \mathrm{SD}$ of predicted), and a relatively rapid increase of HR and RER during unloaded or light exercise intensity can be seen as general clinical indications for deconditioning.

\section{Step 6: Dominant Limitation and Symptom Perception}

Abnormal CPET responses can be caused by multiple physiological systems. When the preponderance of data suggests that one system is dominating this response (eg, cardiovascular abnormalities), this system becomes the primary area of interest allowing for recommendations to target the deficits or referral of the patient to the appropriate medical specialist. Symptom perception of a child should not be overlooked, with special considerations to selfreports before (anamnestic), during, and after performing a CPET. Symptom perception can be divided into subjective perception of a patient and objective physiological signs of exertion. By assessing the subjective perception of a patient, the patient has to describe in their own words (parents should not respond in this case) the primary reason for terminating a CPET. Most often, patients mention leg fatigue, general fatigue, breathlessness, chest pain, dizziness and/or nausea, palpitations, and pain. Subjective perception should be compared with the physiological signs of exertion, as these can be quite different. The degree of discrepancy between subjective and objective indicators may indicate the next steps. For example, drastic differences in perception and physiological responses might prompt further referral (eg, psychosocial issues) or reassurance (no pathology) of the patients and their parents. Indeed, feelings of breathlessness and palpitations are often perceived as negative or dangerous symptoms in children who are not accustomed to exerting themselves.

\section{Step 7: Clinical Interpretation and Pediatric CPET Report}

Efforts to standardize CPET reports have previously been made; however, these are mostly focused on (healthy) adult populations. In our experience with physicians referring children for a CPET,

\section{Table 2 Content of a CPET Report in Pediatric Medicine}

\begin{tabular}{|c|c|}
\hline 1 & Describe the rationale for the CPET \\
\hline 2 & Provide the date of the CPET \\
\hline 3 & $\begin{array}{l}\text { Provide demographic (eg, sex, age, ethnicity); anthropometric (eg, body mass, body mass index); and pulmonary function data, as well } \\
\text { as information concerning the child's level of physical activity and/or sports participation }\end{array}$ \\
\hline 4 & Describe the test protocol used and type of ergometer \\
\hline 5 & Justify the quality of the performed effort, including test duration, symptom perception, and stop reason \\
\hline 6 & Indicate the absolute and relative aerobic capacity $\left(\mathrm{VO}_{2}\right.$ peak $)$ and maximal work rate $\left(\mathrm{WR}_{\text {peak }}\right)$ \\
\hline 7 & $\begin{array}{l}\text { Indicate the absolute and relative (normalized for body mass, expressed as a percentage of } \mathrm{VO}_{2} \text { peak, and expressed as a percentage of } \\
\text { predicted } \mathrm{VO}_{2} \text { peak) ventilatory anaerobic threshold }\end{array}$ \\
\hline 8 & Describe cardiovascular and oxygen transport responses \\
\hline 9 & Describe respiratory responses \\
\hline 10 & Describe gas exchange and ventilation-perfusion matching parameters \\
\hline 11 & Describe muscle metabolism responses \\
\hline 12 & $\begin{array}{l}\text { Provide a clinical interpretation and conclusion concerning the child's aerobic capacity, possible (dominant) limitation(s), and advice } \\
\text { (eg, further referral, personalized training advice, lifestyle advice) }\end{array}$ \\
\hline
\end{tabular}

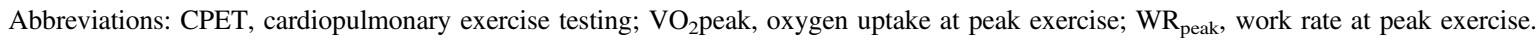




\begin{tabular}{|c|c|c|c|c|c|}
\hline \multicolumn{6}{|c|}{ Cardiopulmonary exercise test report } \\
\hline \multicolumn{6}{|l|}{ Test leader: } \\
\hline Patient ID: & & \multirow{5}{*}{\multicolumn{2}{|c|}{$\begin{array}{r}\text { Age: } \\
\text { Body height: } \\
\text { Body mass: } \\
\text { Body mass index: } \\
\text { Fat free mass: }\end{array}$}} & \multirow{5}{*}{$\begin{array}{lr}\text { years } & \\
\mathrm{cm} & \text { Body height: } \\
\mathrm{kg} & \text { Body mass: } \\
\mathrm{kg} / \mathrm{m}^{2} & \text { Body mass index: } \\
\mathrm{kg} & \text { Fat free mass: }\end{array}$} & \multirow{5}{*}{$\begin{array}{l}z \text {-score } \\
z \text {-score } \\
z \text {-score } \\
z \text {-score }\end{array}$} \\
\hline Name: & & & & & \\
\hline Sex: $\sqrt{n}$ & Male/female & & & & \\
\hline Date of birth: & & & & & \\
\hline Date CPET & & & & & \\
\hline \multicolumn{6}{|c|}{ Reason of CPET referral and specific clinical question: } \\
\hline \\
\hline \multirow{2}{*}{\multicolumn{6}{|c|}{$\begin{array}{r}\text { Family history: } \\
\text { Medical history and medications: }\end{array}$}} \\
\hline & & & & & \\
\hline \multicolumn{6}{|c|}{ Problems/limitations perceived by the patient: } \\
\hline \multicolumn{6}{|c|}{ Problems/limitations perceived by parents/guardians: } \\
\hline \multirow{2}{*}{\multicolumn{6}{|c|}{$\begin{array}{r}\text { Sport and physical activity participation: } \\
\text { Pediatric pre-participation questionnaire: }\end{array}$}} \\
\hline & & & & & \\
\hline \multicolumn{6}{|c|}{\begin{tabular}{|l|l|} 
CPET protocol: & For example, Godfrey $15 \mathrm{~W} / \mathrm{min}$ ramp protocol at a cycle ergometer \\
\end{tabular}} \\
\hline \multicolumn{6}{|l|}{ Resting values } \\
\hline & beats/min & & VE: & FVC: [ & L \\
\hline $\mathrm{O}_{2}$-pulse: & $\mathrm{mL}$ beat & $\mathrm{mL} \min$ & BF: & breaths/min & L \\
\hline BP: & $\mathrm{mm} \mathrm{Hg}$ & $\%$ & TV: & Tiffeneau index: & $\%$ \\
\hline \multicolumn{6}{|c|}{ Quality of the delivered effort } \\
\hline & $\mathrm{HR}_{\text {peak }}: \mathrm{H}$ & beats/min & $H R_{\text {peak }}:[$ & $\%$ of pred. & \\
\hline & RER $_{\text {peak }}:-$ & & & & \\
\hline \multicolumn{6}{|c|}{ Subjective indicators of a maximal effort: For example, fashial flushing and unsteady biking } \\
\hline \multicolumn{6}{|c|}{ Reason(s) for termination the CPET: For example, leg fatigue } \\
\hline \multicolumn{6}{|c|}{ Determining aerobic fitness } \\
\hline & Absolute $\mathrm{VO}_{2 \text { peak }}:$ & Jumin & Absolute $\mathrm{VO}_{2 \text { peak }}:[$ & |z-score & \\
\hline & Relative $\mathrm{VO}_{2 \text { peak }}$ : & $\mathrm{mL} / \mathrm{kg} / \mathrm{min}$ & Relative $\mathrm{VO}_{2 \text { peak }}$ : & z-score & \\
\hline & Absolute $W R_{\text {peak }}:$ & w & Absolute $W R_{\text {peak }}:$ & z-score & \\
\hline & Relative $W R_{\text {peak }}:$ & $W / \mathrm{kg}$ & Relative $W R_{\text {peak }}:$ & $z$-score & \\
\hline & Absolute VAT: & $L$ min & Absolute VAT: & z-score & \\
\hline & Relative VAT: & $\mathrm{mL} / \mathrm{kg} / \mathrm{min}$ & Relative VAT: & z-score & \\
\hline & VAT: & $\%$ of $V_{2 p o a k}$ & VAT: & $\%$ of pred. $\mathrm{VO}_{2}$ & \\
\hline
\end{tabular}

\begin{tabular}{|c|c|}
\hline \multicolumn{2}{|l|}{ Physiological responses } \\
\hline Cardiovascular responses and $\mathrm{O}_{2}$-transport: & 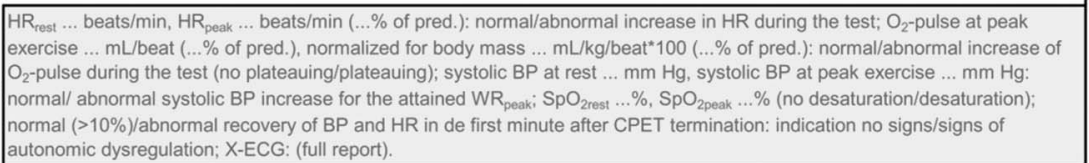 \\
\hline \multirow[b]{2}{*}{ Gas exchange and ventilation-perfusion matching: } & 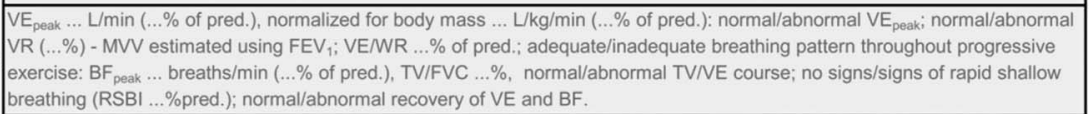 \\
\hline & $\begin{array}{l}\text { Normal/abnormal VEV } / \mathrm{CO}_{2} \text {-slope up to the } \mathrm{RCP}\left(\ldots, \ldots \% \text { of pred.); } \mathrm{P}_{\mathrm{ET}} \mathrm{CO}_{2} \text { at } \mathrm{VAT} \ldots \mathrm{mm} \mathrm{Hg}\left(\ldots \% \text { pred.), EqCO } \mathrm{Eq}_{2} \text { at VAT } \ldots\right.\right. \\
\left(\ldots \% \text { pred.); } \mathrm{P}_{\mathrm{ET}} \mathrm{O}_{2} \text { and } \mathrm{P}_{\mathrm{ET}} \mathrm{CO}_{2} \text { within/outside normal limits. }\right.\end{array}$ \\
\hline Muscle metabolism responses: & $\begin{array}{l}\text { Yes/no premature metabolic acidosis; } R E R \text { peak: ... (...\%pred.): normal/abnormal RER course; } \Delta \mathrm{VO}_{2} / \Delta \mathrm{WR} \ldots \mathrm{mL} / \mathrm{min} / \mathrm{W}(\ldots \% \text { of } \\
\text { pred.): normal/abnormal } \mathrm{O}_{2} \text { cost of work; normal/abnormal recovery of RER/acidosis. }\end{array}$ \\
\hline Deconditioning: & Yes/no clinical indications for deconditioning. \\
\hline
\end{tabular}

\section{Symptom perception}

No signs/signs of dizziness, nausea, headache, hyperventilation, breathlessness, dysfunctional breathing, chest pain, increased palpitations during and after the CPET; main reason to terminate the CPET: leg fatigue/dyspnea/

\section{Clinical interpretation and conclusion}

Report the main findings of the CPET and clearly state whether a most dominant physiological limitation could be distinguished. Moreover, a statement about the risk implications of the physiological limitations and other identified abnormalities should be provided. Finally, the report should provide a clear answer to the clinical question of the referring medical specialist. When of relevance, include possible further referrals, personalized advices regarding lifestyle and habitual physical activity, suggestions for a personalized exercise training program including specific thresholds and training zone and/or specific limitations during exercise.

Figure 2 - Example of a comprehensive pediatric CPET report. BF indicates breathing frequency; $\mathrm{BF}_{\text {peak }}$, breathing frequency at peak exercise; BP, blood pressure; CPET, cardiopulmonary exercise testing; $\mathrm{EqCO}_{2}$, ventilatory equivalent for carbon dioxide; $\mathrm{FEV}_{1}$, forced expiratory volume in $1 \mathrm{~s}$; $\mathrm{FVC}$, forced vital capacity; $\mathrm{HR}$, heart rate; $\mathrm{HR}_{\text {peak }}$, heart rate at peak exercise; $\mathrm{HR}_{\text {rest }}$, heart rate at rest; $\mathrm{MVV}$, maximum voluntary ventilation; $\mathrm{O}_{2}$, oxygen; $\mathrm{O}_{2}$ pulse, oxygen pulse; $\mathrm{P}_{\mathrm{ET}} \mathrm{O}_{2}$, partial end-tidal oxygen tension; $\mathrm{P}_{\mathrm{ET}} \mathrm{CO}_{2}$, partial end-tidal carbon dioxide tension; RCP, respiratory compensation point; RER, respiratory exchange ratio; $\mathrm{RER}_{\text {peak }}, \mathrm{RER}$ at peak exercise; $\mathrm{RSBI}$, rapid shallow breathing index; $\mathrm{SpO}_{2}$, peripheral oxygen saturation; $\mathrm{SpO} \mathrm{O}_{2 \text { peak }}$, peripheral oxygen saturation at peak exercise; $\mathrm{SpO}_{2 \text { rest }}$, peripheral oxygen saturation at rest; $\mathrm{TV}$, tidal volume; TV/FVC, tidal volume to forced vital capacity ratio (depth of breathing); TV/VE, tidal volume to minute ventilation ratio; VAT, ventilatory anaerobic threshold; VE, minute ventilation; VE $\mathrm{Veak}_{\text {, minute }}$ ventilation at peak exercise; $\mathrm{VE} / \mathrm{VCO}_{2}$-slope, slope of the relation between minute ventilation and carbon dioxide production; $\mathrm{VE} / \mathrm{WR}$, minute ventilation to

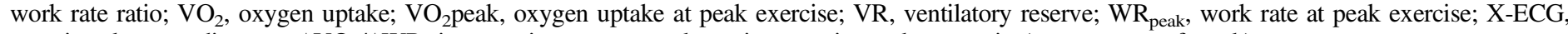
exercise electrocardiogram; $\Delta \mathrm{VO}_{2} / \Delta \mathrm{WR}$, increase in oxygen uptake to increase in work rate ratio (oxygen cost of work). 
the most imperative information they expect is regarding the normalcy of exercise responses, whether dominant limiting physiological elements or even pathophysiological patterns can be observed and whether their clinical question(s) can be answered. Although not all CPET parameters make sense to physicians, a comprehensive and standardized pediatric CPET report including a clear interpretation of the exercise data is indispensable to provide specific feedback to the referring specialist, as well as to other health care professionals. Table 2 and Figure 2 provide a format for a standardized pediatric CPET report. It is important to note that the report also includes a description of any trajectories and slopes of exercise physiological variables from rest up to peak exercise and during recovery, along with the interpretation on whether these findings are normal or require further investigation. Moreover, the report should clearly state whether a CPET revealed a dominant physiological limitation or even uncovered particular pathophysiological patterns. Finally, the report should provide a clear answer to the clinical question of the referring specialist as this, in combination with results from other diagnostic tests (eg, blood and urine analysis, magnetic resonance imaging, or spirometry data), will contribute to establishing a diagnosis or evaluation of the patient. When appropriate, it may be helpful to include potential further referrals, personalized recommendations regarding lifestyle and habitual physical activity, suggestions for a personalized physical exercise training program, and/ or specific limitations or contraindications to exercise.

\section{Conclusions}

Applying a standardized approach to conducting, analyzing, and interpreting the CPET will enhance its value as a clinical tool for diagnostic, prognostic, and evaluative purposes in pediatrics. Detailed analyses of a CPET provide data-driven support for physiological reasoning and clinical decision making across a broader range of medical conditions. Furthermore, it will allow comparisons between clinical centers administering these tests, and in turn a better understanding of the CPET responses.

\section{Acknowledgment}

The authors would like to thank Joyce Obeid for editing of the final manuscript.

\section{References}

1. Akkerman M, van Brussel M, Bongers BC, Hulzebos EHJ, Helders PJ, Takken T. Oxygen uptake efficiency slope in healthy children. Pediatr Exerc Sci. 2010;22(3):431-41. PubMed ID: 20814038 doi: 10.1123/pes.22.3.431

2. American College of Sports Medicine Position Stand and American Heart Association. Recommendations for cardiovascular screening, staffing, and emergency policies at health/fitness facilities. Med Sci Sports Exerc. 1998;30(6):1009-18.

3. American Thoracic Society; American College of Chest Physicians. ATS/ACCP statement on cardiopulmonary exercise testing. Am J Respir Crit Care Med. 2003;15(167):211-77. PubMed ID: 12524257 doi:10.1164/rccm.167.2.211

4. Armstrong $\mathrm{N}$, Winsley R. Is peak $\mathrm{VO}_{2}$ a maximal index of children's aerobic fitness? Int J Sports Med. 1996;17(5):356-9. PubMed ID: 8858407 doi:10.1055/s-2007-972860

5. Barker AR, Williams CA, Jones AM, Armstrong N. Establishing maximal oxygen uptake in young people during a ramp cycle test to exhaustion. Br J Sports Med. 2011;45(6):498-503. PubMed ID: 19679577 doi:10.1136/bjsm.2009.063180

6. Bar-Or O, Rowland TW. Pediatric Sports Medicine for the Practitioner. Champaign, IL: Human Kinetics; 2004.

7. Belardinelli R, Lacalaprice F, Tiano L, Muçai A, Perna GP. Cardiopulmonary exercise testing is more accurate than ECG-stress testing in diagnosing myocardial ischemia in subjects with chest pain. Int $J$ Cardiol. 2014;174(2):337-42. PubMed ID: 24768399 doi:10.1016/j. ijcard.2014.04.102

8. Blanchard J, Blais S, Chetaille P, et al. New reference values for cardiopulmonary exercise testing in children. Med Sci Sports Exerc. 2018;50(6):1125-33. PubMed ID: 29346167 doi:10.1249/MSS. 0000000000001559

9. Bongers BC, van Brussel M, Hulzebos EHJ, Takken T. Pediatric Norms for Cardiopulmonary Exercise Testing: In Relation to Sex and Age. 's-Hertogenbosch, The Netherlands: BOXPress; 2014.

10. Bongers BC, Werkman MS, Takken T, Hulzebos EHJ. Ventilatory response to exercise in adolescents with cystic fibrosis and mildto-moderate airway obstruction. Springerplus. 2014;3(1):696-706. PubMed ID: 25512888 doi:10.1186/2193-1801-3-696

11. Borel B, Leclair E, Thevenet D, Beghin L, Gottrand F, Fabre C. Mechanical ventilatory constraints during incremental exercise in healthy and cystic fibrosis children. Pediatr Pulmonol. 2014;49(3): 221-9. PubMed ID: 23765600 doi:10.1002/ppul.22804

12. Chang RKR, Gurvitz M, Rodriguez S, Hong E, Klitzner TS. Current practice of exercise stress testing among pediatric cardiology and pulmonology centers in the United States. Pediatr Cardiol. 2006; 27(1):110-6. PubMed ID: 16235016 doi:10.1007/s00246-005$1046-9$

13. Connick DM. The role of exercise stress testing in pediatric patients with heart disease. Prog Pediatr Cardiol. 2005;20(1):45-52. doi:10. 1016/j.ppedcard.2004.12.004

14. Cooper CB, Storer TW. Exercise Testing and Interpretation. Cambridge, UK: Cambridge University Press; 2001.

15. Diekman EF, Visser G, Schmitz JPJ, et al. Altered energetics of exercise explain risk of rhabdomyolysis in very long-chain Acyl-CoA dehydrogenase deficiency. PLoS ONE. 2016;11(2): e0147818-19. PubMed ID: 26881790 doi:10.1371/journal.pone. 0147818

16. Dumitrescu D, Rosenkranz S. Graphical data display for clinical cardiopulmonary exercise testing. Ann Am Thorac Soc. 2017;14 Suppl 1:S12-21. PubMed ID: 28541745 doi:10.1513/AnnalsATS. 201612-955FR

17. Fawkner SG. Pulmonary function. In: Armstrong N, van Mechelen W, eds. Paediatric Exercise Science and Medicine. Oxford, UK: Oxford University Press; 2008, pp. 243-53.

18. Forman DE, Myers J, Lavie CJ, Guazzi M, Celli B, Arena R. Cardiopulmonary exercise testing: relevant but underused. Postgrad Med. 2010;122(6):68-86. PubMed ID: 21084784 doi:10.3810/pgm. 2010.11.2225

19. Gelbart M, Ziv-Baran T, Williams CA, Yarom Y, Dubnov-Raz G. Prediction of maximal heart rate in children and adolescents. Clin J Sport Med. 2017;27(2):139-44. PubMed ID: 27177205 doi:10.1097/ JSM.0000000000000315

20. Gibbons RJ, Balady GJ, Beasley JW, et al. ACC/AHA guidelines for exercise testing. J Am Coll Cardiol. 1997;30(1):260-315. PubMed ID: 9207652 doi:10.1016/S0735-1097(97)00150-2

21. Godfrey S. Exercise Testing in Children: Applications in Health and Disease. London, UK:Saunders. 1974.

22. Issekutz B, Birkhead NC, Rodahl K. Use of respiratory quotients in assessment of aerobic work capacity. J Appl Physiol. 2013;17(1): 47-50. doi:10.1152/jappl.1962.17.1.47 
23. Kaafarani M, Schroer C, Takken T. Reference values for blood pressure response to cycle ergometry in the first two decades of life: comparison with patients with a repaired coarctation of the aorta. Expert Rev Cardiovasc Ther. 2017;15(12):945-51. PubMed ID: 28949265 doi:10.1080/14779072.2017.1385392

24. Kotte EMW, de Groot JF, Bongers BC, Winkler AMF, Takken T. Fitkids treadmill test: age- and sex-related normative values in Dutch children and adolescents. Phys Ther. 2016;96(11):1764-72. PubMed ID: 27197825 doi:10.2522/ptj.20150399

25. Levett DZH, Jack S, Swart M, et al. Perioperative cardiopulmonary exercise testing (PCPET): consensus clinical guidelines on indications, organization, conduct, and physiological interpretation. $\mathrm{Br} J$ Anaesth. 2018;120(3):484-500. PubMed ID: 29452805 doi:10.1016/ j.bja.2017.10.020

26. Mezzani A, Agostoni P, Cohen-Solal A, et al. Standards for the use of cardiopulmonary exercise testing for the functional evaluation of cardiac patients: a report from the Exercise Physiology Section of the European Association for Cardiovascular Prevention and Rehabilitation. Eur J Cardiovasc Prev Rehabil. 2009;16(3):249-67. PubMed ID: 19440156 doi:10.1097/HJR.0b013e32832914c8

27. Orenstein DM. Assessment of exercise pulmonary function. In: Rowland TW, ed. Pediatric Laboratory Exercise Testing: Clinical Guidelines. Leeds, UK: Human Kinetics; 1993, pp. 141-63.

28. Quinlivan R, Lucia A, Scalco RS, et al. Report on the EUROMAC McArdle Exercise Testing Workshop, Madrid, Spain, 11-12 July 2014. Neuromuscul Disord. 2015;25(9):739-45. PubMed ID: 26159598 doi:10.1016/j.nmd.2015.05.009

29. Rowland TW. Aerobic exercise testing protocols. In: Rowland TW, ed. Pediatric Laboratory Exercise Testing: Clinical Guidelines. Champaign, IL: Human Kinetics; 1993, pp. 19-41.

30. Rowland TW. Ventilation responses. In: Rowland TW, ed. Children's Exercise Physiology. Champaign, IL: Human Kinetics; 2005, pp. $135-47$.

31. Rowland TW, Cunningham LN. Development of ventilatory responses to exercise in normal white children: a longitudinal study. Chest. 1997;111(2):327-32. PubMed ID: 9041977 doi:10.1378/ chest.111.2.327

32. Rowland TW, Cunningham LN. Oxygen uptake plateau during maximal treadmill exercise in children. Chest. 1992;101(2), p. 485-9. PubMed ID: 1735277 doi:10.1378/chest.101.2.485

33. Sabath R III, White D, Tenson K. Exercise testing protocols. In: Rowland TW, ed. Cardiopulmonary Exercise Testing in Children and Adolescents. Champaign, IL: Human Kinetics; 2018:p.37.

34. Sovtic AD, Minic PB, Kosutic J, Markovic-Sovtic GP, Gajic MB. Static hyperinflation is associated with decreased peak exercise performance in children with cystic fibrosis. Respir Care. 2013;58(2): 291-7. PubMed ID: 22781548 doi:10.4187/respcare.01946
35. Sue DY. Excess ventilation during exercise and prognosis in chronic heart failure. Am J Respir Crit Care Med. 2011;183(10):1302-10. PubMed ID: 21257789 doi:10.1164/rccm.201006-0965CI

36. Sun XG, Hansen JE, Garatachea N, Storer TW, Wasserman K. Ventilatory efficiency during exercise in healthy subjects. Am J Respir Crit Care Med. 2002;166(11):1443-8. PubMed ID: 12450934 doi:10. 1164/rccm.2202033

37. Takayanagi Y, Koike A, Nagayama O, et al. Clinical significance of the overshoot phenomena of respiratory gas indices during recovery from maximal exercise testing. J Cardiol. 2017;70(6):598-606. PubMed ID: 28528994 doi:10.1016/j.jjcc.2017.03.012

38. Takken T, Blank AC, Hulzebos EH, Van Brussel M, Groen WG, Helders PJ. Cardiopulmonary exercise testing in congenital heart disease: (contra)indications and interpretation. Neth Heart J. 2009;17(10):385-92. PubMed ID: 19949648 doi:10.1007/ BF03086289

39. Takken T, Bongers BC, van Brussel M, Haapala EA, Hulzebos EHJ. Cardiopulmonary exercise testing in pediatrics. Ann Am Thorac Soc. 2017;14, Suppl 1:S123-8. doi:10.1513/AnnalsATS.201611912FR

40. Takken T, Groen WG, Hulzebos EH, et al. Exercise stress testing in children with metabolic or neuromuscular disorders. Int $J$ Pediatr. 2010;2010: 1-6. PubMed ID: 20706686 doi:10.1155/ 2010/254829

41. Takken T, Van Brussel M, Hulzebos EHJ, eds. Algemene inspanningsfysiologie. In: Inspanningsfysiologie bij kinderen. Houten, The Netherlands: Bohn Stafleu van Loghum; 2008, pp. 12-27.

42. Tanaka H, Monahan KD, Seals DR. Age-predicted maximal heart rate revisited. J Am Coll Cardiol. 2001;37(1):153-6. PubMed ID: 11153730 doi:10.1016/S0735-1097(00)01054-8

43. Toma N, Bicescu G, Enache R, Dragoi R, Cinteza M. Cardiopulmonary exercise testing in differential diagnosis of dyspnea. Maedica. 2010;5(3):214-8. PubMed ID: 21977155

44. Unnithan V, Rowland TW. Use of oxygen pulse in predicting Doppler-derived maximal stroke volume in adolescents. Pediatr Exerc Sci. 2015;27(3):412-8. PubMed ID: 26186706 doi:10.1123/ pes.2014-0215

45. Urquhart DS, Vendrusculo FM. Clinical interpretation of cardiopulmonary exercise testing in cystic fibrosis and implications for exercise counselling. Paediatr Respir Rev. 2017;24:72-8. PubMed ID: 26515919 doi:10.1016/j.prrv.2015.09.009

46. Wasserman K. Determinants and detection of anaerobic threshold and consequences of exercise above it. Circulation. 1987;76(6):VI29-39. PubMed ID: 3315297

47. Wasserman K, Hansen JE, Sue DY. Principles of Exercise Testing and Interpretation: Pathophysiology and Clinical Applications. Philadelphia, PA: Lippincott Williams \& Wilkins; 2005. 


\section{Appendix: Pediatric Pre-participation Screening Questionnaire}

NAME: es

PATIENT ID: tos

DATE OF BIRTH: 1

TEST DATE: es

SEX: $\square$ MALE $\square$ FEMALE

CURRENT MEDICATION USE:

(i) Determine your/your child's health status by marking what applies to you/your child

Medical history, you have had:

$\begin{array}{cc}\text { YES } & \text { NO } \\ \square & \square \mathscr{e s} \\ \square & \square \mathscr{e s} \\ \square & \square \mathscr{e s} \\ \square & \square \mathscr{e s} \\ \square & \square \mathscr{e s} \\ \square & \square \mathscr{e s} \\ \square & \square \mathscr{e s} \\ \square & \square \mathscr{\text { NOS }}\end{array}$

- Congenital heart disease

- Cardiac rhythm disturbance

- Heart surgery

- Heart failure

- Heart transplantation

- Heart valve disease

- Cardiac catheterization

- Pacemaker/implantable cardiac defibrillator

Symptoms, you:

$\begin{array}{cc}\text { YES } & \text { NO } \\ \square & \square \mathscr{e s} \\ \square & \square \mathscr{e s} \\ \square & \square \mathscr{e s} \\ \square & \square \mathscr{e s} \\ \square & \square \mathscr{e s} \\ \square & \square \mathscr{e s} \\ \square & \square \mathscr{e s} \\ \square & \square \mathscr{\text { NOS }}\end{array}$

- Experience chest pain or chest discomfort during exercise

- Experience unreasonable breathlessness

- Experience a hard or fast beating heart

- Experience dizziness, fainting, or blackouts

Other health issues, you havelare:

- Diabetes mellitus

- Asthma of other lung disease

- Burning or cramping sensations in your legs when walking

- Muscle or joint problems that limit your physical activity

- Concerns regarding the safety of exercise (you or your parents)

- Intoxications (smoking, alcohol, drugs, energy drinks)

- Pregnant

Cardiovascular risk factors:

YES NO

- Blood pressure levels are elevated

- Use of blood pressure medication

- Blood cholesterol level is elevated

- You have a close relative who had a heart attack before the age of 55 years (father/brother) or 65 years (mother/sister)

- You have a close relative who died unexpectedly before the age of 40 years

- You have a close relative who have had a pacemaker/implantable cardiac defibrillator before the age of 40 years

- You have a close relative who have had a cardiac rhythm disturbance before the age of 40 years

- You are physically inactive ( $<30$ minutes of physical activity on at least 3 days a week)

- You are overweight or obese

SIGNATURE PARENTS/GUARDIANS:

NAME: 25

SIGNATURE:

UNKNOWN

$\begin{array}{llr}\text { YES } & \text { NO } & \text { UNKN }\end{array}$

$\square \quad \square \quad \square \mathscr{e s}$

$\square \quad \square \quad \square$

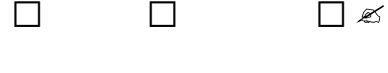

$\begin{array}{lll}\square & \square & \square \mathscr{\&} \\ \square & \square & \square \&\end{array}$

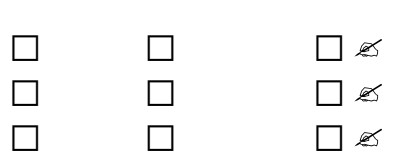

Note: Adapted from Bongers et al (9) drafted by the Child Development \& Exercise Center and the Children's Heart Center of the University Medical Center Utrecht and based upon the original version of the American College of Sports Medicine and the American Heart Association (2). 